\title{
25 jaar externe verslaggevingstheorie
}

\author{
Revolutionaire veranderingen
}

Prof.Dr. D.W. Feenstra

\section{Inleiding}

In 1971 karakteriseerde Nelson (p.4) de jaren zestig van de twintigste eeuw als volgt: 'The decade of the 1960's was a golden age in the history of a priori research in accounting'. Tot de bekendste werken uit deze periode behoren de studies van Edwards en Bell (1961), Chambers (1966), ljiri (1967) en Sterling (1970). Bouma's dissertatie en oratie (1966, respectievelijk 1967) zouden in deze reeks niet hebben misstaan. In dit artikel zullen wij een impressionistisch en subjectief overzicht geven van hoofdlijnen in de ontwikkeling van het vakgebied der externe verslaggeving vanaf het midden der jaren zestig, waarbij regelmatig zal worden verwezen naar in Bouma's studies voorkomende opvattingen.

Het bestek van dit artikel dwingt ons tot compactheid. Wij hebben daarom gekozen voor een comparatief-statische aanpak. $\mathrm{Na}$ het midden der jaren zestig zal de stand van zaken aan het eind der jaren zeventig worden beschreven, waarna wordt afgesloten met een karakterisering van de huidige stand van zaken en een visie op toekomstige ontwikkelingen. Onze drie momentopnamen duiden we achtereenvolgens aan met '1966', '1979' en '1991'. Men vatte deze jaartallen niet al te letterlijk op: met '1966' bedoelen we de periode van enkele jaren rondom het jaar 1966; mutatis mutandis geldt hetzelfde voor '1979' en '1991'. Er zal worden gekeken naar paradigmatische ontwikkelingen, het institutionele kader en kernthema's in de literatuur. Onze invalshoek zal zowel nationaal als internationaal (lees: gericht op de USA) zijn. Betoogd zal worden dat zich in een tijdsbestek van 25 jaren revolutionaire verande- ringen hebben voorgedaan op het terrein der externe verslaggeving; in Bouma's dissertatie en oratie kan men diverse aanzetten voor deze veranderingen aantreffen.

\section{6}

Bouma's dissertatie en oratie werden in de hoogtijdagen van de deductieve benaderingswijze van het vakgebied der externe verslaggeving gepubliceerd. Deze benaderingswijze wordt gekenmerkt door pogingen tot formuleringen van logisch sluitende theorieën met een relatief sterke voorkeur voor de 'waarde- en winstproblematiek', waarbij het economisch winstbegrip veelal als ideaal en als uitgangspunt wordt gehanteerd. De theorieën kunnen zijn gebaseerd op empirisch toetsbare uitgangspunten (postulaten) en/of redelijke aannames. In het eerste geval spreekt men van empirisch apriorisme, in het tweede geval van rationalistisch apriorisme. Het empirisch apriorisme leidt tot relatief sterk beschrijvende ('descriptive') theorieën. Het rationalistisch apriorisme kan tot tamelijk abstracte theorieën leiden. De deductieve benaderingswijze kan gezien worden als een reactie op de in de eerste helft van de twintigste eeuw dominante en heden ten dage nog steeds populaire empirisch-inductieve benadering, die gekenmerkt wordt door ex post rationalisaties van de bestaande verslaggevingspraktijk (Whittington, 1986). De empirisch-inductieve benaderingswijze heeft voor de verslaggevings-

Prof. Dr. D. W. Feenstra is hoogleraar in de Financieel Administratieve Bedrijfseconomie aan de Rijksuniversiteit Groningen. Hij is in 1985 gepromoveerd bij Prof. Dr. J. L. Bouma op het proefschrift 'Oordeelsvorming rond de Externe Berichtgeving'. 


\section{MAB}

praktijk uiterst belangrijke concepten opgeleverd, zoals het voorzichtigheidsprincipe, de realisatieconventie en het matching-beginsel. Sterling (1967, p.98) karakteriseerde deze benaderingswijze daarom eens als 'matching and attaching'. Het verschil tussen het empirisch apriorisme en de empirisch-inductieve benaderingswijze is soms gradueel. Duidelijk komt dit bijvoorbeeld tot uitdrukking in Thomas' studies over het allocatieprobleem $(1969,1974)$. Dat deductie en inductie elkaar niet behoeven uit te sluiten, maar elkaar kunnen aanvullen is een gedachte die we overigens uit De Groots (1961) empirische cyclus kennen. Bedenkt men tevens dat zowel de deductieve als de empirisch-inductieve benaderingswijze beschrijvend (positief) dan wel vóorschrijvend (normatief) kunnen worden gehanteerd, dan wordt duidelijk dat beide benaderingswijzen veeleer in elkaars verlengde liggen dan elkaars tegenpolen zijn.

In Nederland bestond in 1966 in universitaire kringen een sterke voorkeur voor de logisch-deductieve benaderingswijze. Op het terrein der externe verslaggeving leidde dit soms tot sterk normatief getinte pleidooien voor toepassing van (varianten van) Limpergs vervangingswaardetheorie. In het bijzonder naar aanleiding van de voorstellen over de wettelijke regeling van de jaarrekening van ondernemingen, ontspon zich een discussie rond de vraag of deze vervangingswaardetheorie de bedrijfseconomisch aanvaardbare grondslagen voor de gepubliceerde jaarrekening kan verschaffen. In Burgerts preadvies voor de accountantsdag 1967 werd daar na een zeer grondige analyse ernstig aan getwijfeld (1967). Messcherp wees Burgert op enkele ernstige tekortkomingen van de vervangingswaardetheorie, zoals: de subjectieve inhoud van het begrip normale voorraad en het onopgeloste vraagstuk van niet-identieke vervanging in een dynamische werkelijkheid. Burgert baseerde zich vervolgens bij de door hem voorgestelde waarde- en winstconceptie op de gedachten van Edwards en Bell zoals tot uiting komend in hun begrip Business Profit.

Burgerts opvattingen uit 1967 gingen velen te ver. Onzes inziens werd aan zijn preadvies aanvankelijk nauwelijks aandacht besteed; discussies naar aanleiding van dit preadvies kan men in de Nederlandse literatuur niet aantreffen. Volgens Burgerts discussiant - Bouma - gingen diens opvattingen in bepaalde opzichten evenwel niet ver genoeg. De door Burgert, in navolging van Edwards en Bell, bepleite splitsing van de vermogensaanwas over een periode in een resultaat op verkopen op vervangingswaardebasis en een voorraadresultaat op voorraden en vaste activa werd door Bouma aangevochten, niet omdat het realisatieprincipe werd verlaten, maar op grond van de in zijn proefschrift gegeven analyse van de implicaties van het onzekerheidsverschijnsel op de winstbepaling. Daar heeft Bouma onder andere betoogd dat onder onzekerheid de ontwikkeling van de kapitaalwaarde in de loop der tijd niet langer voorzienbaar is, waardoor er geen theoretisch eenduidige wijze bestaat de toename van de kapitaalwaarde te verdelen in een uitkeerbare transactiewinst en een niet uitkeerbare 'holding gain'. Voorts werden begrippen als continuïteit en levensvatbaarheid door hem niet langer in verband gebracht met een in de vervangingswaardetheorie niet verklaard begrip als normale produktieomvang, maar met de voor de leiding van een organisatie relevante aspiratieniveaus. Verschillende ondernemingsdoelstellingen en schattingen inzake toekomstige ontwikkelingen en het bestaan van aspiratieniveaus impliceren het bestaan van vele mogelijke uitkomsten in het winstberekeningsproces. Een enkeling gingen deze opvattingen van Bouma zo ver, dat deze ter plaatse van 'communistische sympathieën' werd beschuldigd, een kwalificatie waar latere studentengeneraties waarschijnlijk geen enkel begrip voor kunnen opbrengen. In de internationale literatuur kan men Bouma's opvattingen rond de implicaties van het onzekerheidsverschijnsel heden ten dage aantreffen in serieuze wetenschappelijke werken.

De empirisch-inductieve benaderingswijze is voor de verslaggevingspraktijk van grote betekenis; ze zal dat in de toekomst waarschijnlijk wel blijven ook. Voor de evaluatie van de gangbare praktijk en voor de ontwikkeling van standaards voor de verslaggeving is ze in elk geval belangrijk geweest (zie bijvoorbeeld Grady's Accounting 
Research Study no. 7 uit 1965). Toch is er een belangrijk bezwaar: de benaderingswijze is niet produktief als het gaat om de ontwikkeling van nieuwe problemen. In de internationale literatuur is men van mening dat van een deductieve benaderingswijze meer verwacht mag worden. Omstreeks 1966 heeft men nog hoge verwachtingen van de zogenoemde 'true income'-variant van de deductieve benadering. Nederland liep in die tijd keurig in de pas met de internationale ontwikkelingen. Ook in het buitenland vormde de economische theorie vaak een belangrijk startpunt en referentiekader voor de vele theorieën die werden ontwikkeld (zie bijvoorbeeld de bundel van Parker en Harcourt (1969) voor een beeld van deze soms sterk verschillende theorieën). De verschillende standpunten betreffende de waardeen winstconcepties ontlokten veelvuldig bij practici de verzuchting dat de theoretici eerst maar eens moeten zorgen voor eenheid in opvattingen alvorens de praktijk de les te lezen. Een van de reacties op deze kritiek vanuit de praktijk was een versterkte aandacht voor empirisch onderzoek waarbij die theorieën werden verworpen dan wel geamendeerd waarvan de vooronderstellingen of de voorspellingen strijdig bleken te zijn met de resultaten van empirisch onderzoek. Een andere reactie was de relativering van het 'true-income'adagium tot een 'different incomes for different purposes'-benadering, zoals we dat bij Edwards en Bell reeds aantroffen. Beide reacties zullen wij in het navolgende nog tegenkomen.

De 'true income'-variant vormde anno 1966 ongetwijfeld de dominante stroming binnen de deductieve benaderingswijze. Van grote betekenis voor de latere ontwikkelingen bleek een publikatie van de American Accounting Association uit 1966, getiteld A Statement of Basic Accounting Theory (ASOBAT). Deze in Nederland aanvankelijk niet of nauwelijks opgemerkte publikatie legde een conceptuele basis voor het latere Conceptual Framework Project van de FASB. De relatief sterke accentuering van de communicatiefunctie in de definitie van accounting bracht Sterling (1967, p.99) er zelfs toe te verklaren, dat hier sprake zou kunnen zijn van 'the most significant development since Pacioli'. Sterling doelde daarmee in het bijzonder op het destijds voor de Ame- rikaanse verslaggevingspraktijk methodologisch gezien revolutionaire voorstel 'to establish standards for judging the acceptability of accounting standards' (ASOBAT, p.6). De in ASOBAT gegeven definitie luidt (p.1): '...accounting as the process of identifying, measuring, and communicating economic information to permit informed judgements and decisions by users of the information'. Gecombineerd met een sterke nadruk op de 'basic standard' relevantie werd hiermee de basis gelegd voor een tweede variant van de deductieve benaderingswijze, en wel de gebruikersbenadering. Opmerkelijk is dat Bouma's voorstel om in de externe verslaggeving waar nodig met waarschijnlijkheidsverdelingen te werken reeds in ASOBAT voorkomt. Dat relevantie wel eens op gespannen voet kan staan met beperkt rationele besluitvorming wordt overigens in ASOBAT niet opgemerkt. Men ziet geen bezwaren tegen het opnemen in de jaarrekening in twee kolommen naast elkaar van zowel vervangingswaarde als historische kosten. De gebruikersbenadering ging in de loop van de jaren zeventig langzamerhand de 'true-income'variant overheersen, ook al sputterde de beroepsorganisatie van Amerikaanse accountants aanvankelijk nog tegen, getuige Accounting Principles Board Statement no. 4 uit 1970, waarin de empirischinductieve benaderingswijze nog onverkort werd aangehangen.

Op institutioneel gebied werd anno 1966 in Nederland gediscussieerd over de op til zijnde wettelijke regeling. Huizenga (1969) heeft deze discussie betrekkelijk gedetailleerd samengevat in zijn proefschrift. In de Verenigde Staten werd het 'matching and attaching'-denken door de Accounting Principles Board in haar Opinions en Accounting Research Studies enthousiast aangehangen (bijvoorbeeld in ARS no. 9 en APB no. 11 over latente belastingverhoudingen). 'Nieuwlichters' als Moonitz en Sprouse hadden in ARS no. 3 weliswaar voorstellen gedaan die ten dele samenvielen met die in ASOBAT, zij werden evenwel door de beroepsorganisatie gedesavoueerd.

Gedragswetenschappelijke studies waren op het terrein der verslaggeving anno 1966 schaars. De 


\section{MAB}

enkele (buitenlandse) studies die er waren hadden voornamelijk betrekking op de interne verslaggeving. In Bouma's proefschrift zijn de bevindingen ervan samengevat.

\section{9}

Het beeld dat wij van het vakgebied der externe verslaggeving anno 1979 zullen schetsen wijkt sterk af van dat anno 1966. Methodologisch gezien valt er een accentuering van het empirisch onderzoek ten koste van de deductieve benaderingswijze op te merken. Beschouwingen over het winstbegrip worden steeds minder aangetroffen; er wordt aansluiting gezocht met andere vakgebieden, zoals de moderne financieringstheorie en de gedragswetenschappen. Institutioneel bekeken zijn er veranderingen te constateren in het juridische kader: in Nederland in de vorm van BW 2 Titel 6 en de uitspraken van het Tripartiete Overleg, in de Verenigde Staten in de vorm van de installatie van de FASB en de formulering van een Conceptual Framework voor de verslaggeving.

Benaderen we 1979 methodologisch, dan constateren we een algemeen gevoel van wetenschappelijk onbehagen. De beperkingen van zowel de inductieve als de deductieve benaderingswijze werden onderkend, een groot deel van het snel populair geworden empirische onderzoek ontbrak het aan theoretische onderbouwing. Het onbehagen uitte zich ondere andere naar aanleiding van een artikel van Wells (1976) in The Accounting Review waarin hij zich, de gedachtengang van Kuhn (1962/1970) volgende, afvroeg of accounting zich in een crisissituatie bevindt en of er daarom revolutionaire paradigmatische veranderingen vallen te verwachten. In de volgende discussie kwam onder meer de vraag naar het wetenschappelijke karakter van accounting naar voren, alsmede de vraag naar wat nu eigenlijk precies onder een paradigma diende te worden verstaan. Knoops (1990) heeft de discussies rond deze twee vragen vorig jaar nog duidelijk gestructureerd samengevat, zodat wij er nu aan voorbijgaan. Wij merken hier slechts op dat velen in accounting geen wetenschappelijke discipline zagen en dat er soms wel een zeer enge betekenis aan het begrip paradigma werd toegekend. Wells bijvoorbeeld beschouwt in wat hij als 'disciplinaire matrix' aanduidt het waarderen op historische kosten als een paradigma.

Nergens komt het methodologische onbehagen zo duidelijk naar voren als in Statement on Accounting Theory and Theory Acceptance (SATTA) van de American Accounting Association uit 1977. Van het optimisme van ASOBAT uit 1966 is weinig over: '.... there are no easy theoretical answers to many of the urgent problems faced by the profession' (1977, p.1x), en: '.... a single universally accepted basic accounting theory does not exist at this time' $(1977$, p.1). In SATTA wordt vervolgens een beschrijving gegeven van vele theorieën; tevens wordt getracht een verklaring te verstrekken voor het naast elkaar bestaan van zoveel onderling verschillende accountingtheorieën, waarbij in navolging van Kuhn over paradigma-aanvaarding werd gesproken (1977, hoofdstuk 4). Uiteindelijk werd de nogal ontmoedigende conclusie getrokken dat een discussie over paradigmata niet kan worden afgerond door inductie en/of deductie, maar slechts door een wijziging in 'Gestalt', dat wil zeggen de wijze waarop men 'de wereld' en 'de werkelijkheid' ziet. De 'boodschap' van SATTA komt per saldo als tamelijk triviaal over: (a) 'theory closure cannot be dictated' (p.49); (b) 'external reporting theory has a wider scope than that which has been generally perceived' (p.49); (c) 'all theory approaches are flawed when viewed from the perspective of some alternative approach' (p.50); (d) 'until consensus paradigm acceptance occurs, the utility of accounting theories in aiding policy decisions is partial' (p.51).

Ook in Nederland was sprake van onvrede over de fundamenten. Deze onvrede had veeleer betrekking op de bedrijfseconomie in het algemeen dan op de externe verslaggeving in het bijzonder. Anno '1979' werd het ongenoegen verwoord in Bosmans Metatheorie (1977) en door Traas (1981). Bosman benadrukte vooral de betekenis van de besluitvormingstheorie, terwijl Traas tevens wees op de rol van de organisatietheorie.

Toen SATTA werd gepubliceerd had zich inmiddels een belangrijke vakinhoudelijke verschuiving 


\section{MAB}

voorgedaan van 'true-income'-debatten naar een oriëntatie op de informatiebehoeften van gebruikers. Binnen het vakgebied der externe verslaggeving kreeg men, geheel passend in de tijdgeest van de jaren zeventig en in de lijn van ASOBAT, meer oog voor de communicatiefunctie van de verslaggeving. Naast ASOBAT leverden vooral het Amerikaanse Trueblood-report (1973) en het Engelse Corporate Report (1975) prikkels voor een ruimere visie. Het blikveld werd verruimd, onder meer tot uiting komend in aandacht voor onderwerpen als personeelsbeleid, 'Human Information Processing', 'Human Resource Accounting' en 'Social Accounting' (Libby, 1981; Schreuder, 1981). De ontwikkelingen werden in belangrijke mate gestimuleerd door en gekanaliseerd in het door Hopwood gestarte tijdschrift Accounting, Organizations and Society. Relevantie voor de besluitvorming was het kernthema geworden voor het snelgroeiende wetenschappelijke onderzoek, waarbij empirisch onderzoek een steeds belangrijker plaats was gaan innemen. De gegroeide variatie in onderzoekthema's bracht haast automatisch een uitbreiding van toegepaste methoden en technieken van onderzoek met zich mee. Aanvankelijk werd relevantie vooral gerelateerd aan beslissingsmodellen (ondere ander Revsine, 1973) en is er slechts sprake van een gradueel verschil met de 'true-income' variant. Een groot bezwaar van de beslissingsmodellen-aanpak is evenwel de gerichtheid op de groepering der aandeelhouders. Ontwikkelingen in de financieringstheorie leverden anderzijds een belangrijke impuls voor empirisch onderzoek naar de relaties tussen de externe verslagggeving en de reacties van beleggers op de vermogensmarkt (Foster, 1978). Voor vele onderzoekers was de oriëntatie op slechts één belangengroep, i.c. de aandeelhouders, te eng. Ook waren velen niet overtuigd van de betekenis van uit de financieringstheorie geïmporteerde concepten als het 'capital asset pricing model' en de 'efficiënte markt hypothese' voor de externe verslaggeving. Ball en Brown's (1968) 'abnormal performance index' werd slechts in een kleine kring van onderzoekers van belang geacht. Enquêtes en interviews wonnen evenwel snel aan betekenis (bijvoorbeeld Lee en Tweedie, 1977), naast een onderzoektechniek als het gecontroleerde experiment, teneinde een beter inzicht te krijgen in de feitelijke informatiewensen en beslissingsprocessen van de gebruikers van de externe verslaggeving. In de vloedgolf van het opkomende empirische onderzoek in de jaren zeventig verdween de theoretische fundering soms wel erg naar de achtergrond. De bezinning waartoe SATTA in 1977 feitelijk opriep is daarom goed verklaarbaar. Een en ander neemt niet weg dat anno '1979' de wetenschappelijke inzichten rond vragen naar de toereikendheid, het nut, de wensen en de relevantie van de externe verslaggevinginformatie veel beter onderbouwd zijn dan anno '1966'.

Aan de betekenis van de in de loop der jaren verkregen theoretische en empirisch gefundeerde inzichten voor de praktijk van de externe verslaggeving werd soms ernstig getwijfeld. Geheel in de lijn van SATTA werd omstreeks dezelfde tijd tijdens een symposium aan de Duke University (Abdel-khalik, Keller, 1978) onder andere opgemerkt: '.... a survey of the accounting literature over the past ten years provides little reason to believe apriori research causes changes in accounting practice' (1978, p.2); en: 'The impact of behavioral research on accounting practice has been almost nonexistent' (p.87); ten slotte: 'At present, empirical research cannot offer much help for policy-makers ...' (p.168). Welke onderzoekmethode ook gebruikt wordt, de betekenis voor de praktijk van de verslaggeving achtte men dus verwaarloosbaar. Wij beschouwen het zojuist verwoorde pessimisme als niet gerechtvaardigd en wijzen ter ondersteuning van dit standpunt met name op de invloed die opvattingen zoals verwoord in het zogenoemde 'Trueblood-report' (AICPA, 1973) hebben gehad bij de totstandkoming van de FASB in 1973 en het door diezelfde FASB opgestarte Conceptual Framework Project. In Engeland en Canada hebben The Corporate Report (1975) respectievelijk Stamp's Corporate Reporting: Its Future Evolution (1980) soortgelijke effecten gesorteerd. Het pessimisme van SATTA en het Duke Symposium past ons inziens beter bij APB Statement no. 4 uit 1970, een document van het AICPA waarin tautologische definities van bijvoorbeeld 'assets' en 'liabilities' zon- 


\section{MAB}

der schroom op papier werden gezet. Anno ' 1979 ' is de kritiek daarop echter achterhaald.

De zowel inhoudelijke als methodologische verbreding en verdieping van het vakgebied werden in Nederland 'op afstand' gevolgd. Velen misten echter de 'wetenschappelijke demarrage' van de jaren zeventig. Voor zover er buitenlandse ontwikkelingen vielen te bespeuren ter zake van waarde- en winstopvattingen, 'reed men attent mee in het peloton' (bijvoorbeeld: Slot en Vijn, 1977), zonder overigens zelf te demarreren, afgezien van Klaassens dissertatie uit 1975. Deze dissertatie paste geheel in de eerder genoemde empirische bezinning op de premissen van de aprioristisch ontwikkelde vervangingswaardetheorie. Ook op het terrein der sociale verslaggeving hoefde men niet te 'lossen'. Met betrekking tot het gedragswetenschappelijk onderzoek, de 'human information processing' en het op de financieringstheorie gebaseerde accountingonderzoek werden de Nederlandse beoefenaren van het vakgebied echter fors 'los gereden'. De eerder genoemde publikaties van Bosman (1977) en Traas (1981) kan men interpreteren als pogingen hier verandering in aan te brengen, door aandacht te vragen voor een bezinning op de fundamenten van het vakgebied der bedrijfseconomie in het algemeen. Deze publikaties demonstreren dat Bouma's oproep uit 1966 om meer aandacht te besteden aan de betekenis van verschijnselen als beperkte rationaliteit, onzekerheid, dynamiek en de scheiding van leiding en eigendom nog gehoor vonden. Methodologisch gezien viel de aandacht voor inventarisaties, enquêtes en interviews op, vooral rond de toepassing van de Wet op de Jaarrekening van Ondernemingen - en rond een typisch fenomeen van de jaren zeventig, namelijk de sociale verslaggeving. Deductieve theorievorming was daarbij vaak ondergeschikt, hypothesetoetsing eveneens, zo al niet geheel afwezig. Het klassieke 'matching and attaching'denken bereikte een hoogtepunt in de dissertatie van Van Hoepen (1981) over de problematiek rond de latente belastingverhoudingen. Dat zich inmiddels in het buitenland een 'accounting revolution' (Beaver, 1981) bezig was te voltrekken, speelde in het Nederlandse krachtenveld geen rol van betekenis. De opkomst van de informatieeconomie als derde variant van de deductieve benaderingswijze (na de 'true-income'- en de gebruikersbenaderingswijze), staat in deze revolutie centraal. Wij sluiten onze beschouwing van '1979' af met enkele opmerkingen over deze nieuwe tak van wetenschapsbeoefening.

De essentie van de informatie-economie is dat informatie als een economisch goed wordt beschouwd waarvoor een markt bestaat waarop vraag en aanbod elkaar ontmoeten. De kosten en baten van de informatieverschaffing worden daarbij expliciet in beschouwing genomen, hetgeen in de hiervoor besproken gebruikersbenaderingswijze niet of nauwelijks het geval is. De informatie-economie levert belangrijke inzichten op voor het proces der regelgeving (Beaver, 1981). Een eerste inzicht heeft te maken met de efficiënte-marktgedachte. Een tweede inzicht hangt samen met de economische gevolgen van openheid in de verslaggeving. In een efficiënte markt is het onmogelijk om systematisch en gemiddeld een meer dan 'normaal' rendement te behalen op basis van gegevens uit de externe verslaggeving. Het begrip 'normaal' dient daarbij geïnterpreteerd te worden vanuit het CAPM-denken. In de academische wereld bestaat er een redelijke consensus over de geldigheid van de 'semistrong' variant van de efficiënte-marktgedachte. Het maakt dan niet uit in welke vorm en waar informatie in een jaarrekening wordt verstrekt. In een efficiënte markt weet men als het ware te discrimineren tussen vorm en inhoud. Vormdiscussies binnen regelgevende organen zijn in dat geval niet zinvol.

Het tweede inzicht samenhangend met de informatie-economie vloeit voort uit de discussies naar aanleiding van de argumenten vóór en tegen regelgeving. Waarom er in feite regelgeving van de externe verslaggeving is valt mede dankzij het begrippenkader van de informatie-economie beter te verklaren dan voorheen. Begrippen als collectief goed, 'free-rider', 'adverse selection' en 'moral hazard' behoren inmiddels ook tot het jargon van het vakgebied der externe verslaggeving. Momenteel worden de bedoelde discussies vaak in een agency-context geplaatst. Daarmee heb- 


\section{MAB}

ben wij onze laatste momentopname bereikt: '1991'.

\section{1, en verder?}

De desillusies naar aanleiding van de aprioristische theorieën van de jaren zestig stimuleerden enerzijds het empirisch onderzoek in de jaren tachtig, anderzijds werd intensief gewerkt aan de ontwikkeling van nieuwe toetsbare theorieën. Whittington (1986, p.24) betitelt de nieuwe stroming waarin theorievorming en toetsing meer dan daarvoor hand in hand gaan als 'The New Empirism'. De sterkste stimulansen gingen uit van economisten uit Chicago en Rochester (zie bijvoorbeeld: Watts en Zimmerman, 1986). De werkwijze en opvattingen van aanhangers van deze nieuwe richting, beter bekend als 'positive accounting theory', ontmoetten echter ook ernstige kritiek (bijvoorbeeld: Christenson, 1983; Chua, 1986; Knoops, 1990, Sterling, 1990; Whittington, 1987). Kernpunten van de kritiek zijn: (a) de denigrerende wijze waarop het aprioristisch onderzoek soms als onwetenschappelijk werd afgedaan, illustreert een gebrek aan inzicht in het complementair zijn van theorie en empirie; (b) het is overtrokken niet toetsbare theorieën als nutteloos af te doen; (c) empirisch onderzoek kan evenzeer als deductief theoretisch onderzoek normatief worden geïnterpreteerd. Het gaat te ver de 'positieve accounting' per definitie als niet normatief te beschouwen; met name Watts en Zimmerman overgieten hun positieve theorie met een flinke dosis normativiteit; (d) de impliciete veronderstelling dat in de werkelijkheid waarneembare fenomenen als organisaties en verslaggeving onafhankelijk zijn van het onderzoek ervan is niet houdbaar. Watts en Zimmerman hebben de methodologische kritiek op hun Friedmaniaanse opvattingen onzes inziens onvoldoende weten te weerleggen (1990).

De uitbouw van de informatie-economische benaderingswijze in de vorm van de agency-theorie en de transactiekostentheorie is per saldo tot nu toe evenwel erg produktief geweest, zowel theoretisch als empirisch, zowel voor de interne als voor de externe verslaggeving. Opvallend in deze benaderingswijzen is de economische invalshoek; de empirische bevindingen van het gedragswetenschappelijke onderzoek, in het bijzonder van het cognitief-psychologische onderzoek, spelen daarbij vooralsnog een volstrekt ondergeschikte rol.

Niettemin heeft het gedragswetenschappelijke empirische onderzoek inmiddels goed gedocumenteerd gedemonstreerd hoe beperkt rationeel menselijke beslissingsprocessen feitelijk verlopen. Op een veel onderzocht en nauw met de externe verslaggeving verwant gebied als bijvoorbeeld dat van de audit-research, komt dit duidelijk naar voren (Feenstra, 1988; Limperg Instituut, 1990). De integratie van een economische en gedragswetenschappelijke invalshoek blijft een grote uitdaging voor de toekomst. Watts en Zimmerman (1990, p.153) verwoorden ons standpunt: 'The major breakthroughs are likely to come from viewing accounting as a choice that is endogenous with the choice of organization, contracting and financial structures'. Op de inhoud van de vele onderzoekingen van de jaren tachtig zullen wij hier niet ingaan (zie bijvoorbeeld: Beaver, 1989; Griffin, 1987). De variatie in thema's blijkt buitengewoon groot te zijn vergeleken met het startpunt van ons overzicht. Eén thema noemen wij hier slechts, en wel dat der regelgeving. Informatie-economie, agency-theorie en transactiekosteneconomie hebben nuttige kaders geleverd voor vraagstellingen die anno '1979' niet of nauwelijks werden gehoord. $E r$ is dientengevolge een theoretisch hoogstaande discussie gevoerd over de argumenten pro en contra de regelgeving van de externe verslaggeving: deze discussie is onlangs nog door Maijoor in zijn proefschrift samengevat (1991; zie ook: Feenstra, 1985; Beaver, 1989). Aan andere onderzoekthema's moeten wij nu voorbij gaan: onderzoek naar relaties tussen externe verslaggeving en de vermogensmarkt inclusief het gebruik van gegevens door individuen, statistische eigenschappen van accountinggrootheden zoals winstcijfers, de voorspellende betekenis van accountinginformatie en naar de verschillen tussen experts en leken bij het vellen van oordelen en het nemen van beslissingen op basis van accountinginformatie. Belangrijk is het door dit onderzoek verkregen inzicht dat de 'bottom-line'-oriëntatie op de 
winst- en verliesrekening niet overheerst bij de gebruikers van jaarrekeningen.

Juridische discussies over het institutionele kader hebben een ondergeschikte positie gekregen tegen de achtergrond van de vloedgolf van empirisch onderzoek. Geheel anders is het beeld van het Nederlandse accounting onderzoek, waar relatief veel aandacht is voor en wordt besteed aan complicaties rond de invoering van Richtlijnen van de RVJ, de EG, het IASC en aan niethypothese gefundeerde empirische onderzoekingen naar de praktijk van de externe verslaggeving. Klaassen en Schreuder gaven in 1984 onder andere een analyse naar thema's van de in de Nederlandse literatuur verschenen Financial Accounting artikelen over de periode 1967-1981. Uitbreiding van deze analyse over de periode 1982-1990 verandert het door hen geschetste beeld niet: aan verslaggevingstechnische onderwerpen wordt relatief veel aandacht geschonken, ook de waarderingsproblematiek blijft de gemoederen bezig houden, evenals juridische aspecten; hypothesetoetsing in de lijn van de 'positive accounting' blijft sterk onderbelicht. Enerzijds is onze kennis van de praktijk van de externe verslaggeving met name dankzij de Rotterdamse Jaar in-jaar uit-publikaties zowel zeer gedetailleerd als diepgaand geworden (zie ook: Brezet en Dijksma, 1988), anderzijds lijkt juist daardoor de aansluiting met de internationale ontwikkelingen niet dichterbij gekomen. Het is tijd voor een demarrage teneinde de achterkant van het internationale wetenschappelijke wielerpeloton in zicht te krijgen! Aan thema's geen gebrek. Bouma gaf in 1966 al de volgende voorbeelden: welke betekenis hebben verschijnselen als onzekerheid, dynamiek, beperkte rationaliteit en de scheiding van leiding en eigendom (agency-relaties) voor de externe verslaggeving? De wijze waarop is duidelijk: methodologische bezinning, theorievorming en empirische toetsing dienen hand in hand te gaan.

\section{Literatuur}

Abdel-khalik, A.R. en Th.F. Keller (eds.) (1978), The Impact of Accounting Research on Practice and Disclosure, Duke Univerity Press.

Accounting Standards Steering Committee (1975), The Corporate Report, Londen.

American Accounting Association (1977), Statement on Accounting Theory and Theory Acceptance.

American Institute of Certified Public Accountants (1962), A Tentative Set of Broad Accounting Principles for Business Enterprises, Accounting Research Study no. 3, R.T. Sprouse, M. Moonitz.

American Institute of Certified Public Accountants (1966), Interperiod Allocation of Corporate Income Taxes, Accounting Research Study no. 9.

American Institute of Certified Public Accountants (1967), Accounting for Income Taxes, Accounting Principles Board. Opinion no. 11.

American Institute of Certified Public Accountants (1970), Basic Concepts and Accounting Principles Underlying Financial Statements of Business Enterprises, Accounting Principles Board, Statement no. 4.

American Institute of Certified Public Accountants (1973), Study Group on the Objectives of Financial Statements, Objectives of Financial Statements, New York.

Ball, R.J. en P. Brown (1968), An Empirical Evaluation of Accounting Income Numbers, Journal of Accounting Research, pp. 159-177.

Beaver, W.H. (1981), Financial Reporting: An Accounting Revolution, Prentice-Hall, Englewood Cliffs, $2^{\text {nd }}$ ed. 1989.

Bosman, A. (1977), Een metatheorie over het gedrag van organisaties, Stenfert Kroese, Leiden.

Bouma, J.L. (1966), Ondernemingsdoel en winst, Stenfert Kroese, Leiden.

Bouma, J.L. (1967), De toepassing van intern-gedragsmodellen in de bedriffseconomie, oratie, Stenfert Kroese, Leiden.

Brezet J.C. en J. Dijksma (red.) (1988), 75 Jaar Bedriifseconomisch Onderzoek op basis van Gepubliceerde Jaarrapporten, Erasmus Universiteit Rotterdam.

Burgert, R. (1967), Bedrijfseconomisch aanvaardbare grondslagen voor de gepubliceerde jaarrekening, De Accountant, september 1967, pp. 153-192.

Chambers, R.J. (1966), Accounting, Evaluation and Economic Behavior, Prentice-Hall, Englewood Cliffs.

Christenson, C. (1983), The Methodology of Positive Accounting The Accounting Review, januari 1983, pp. 1-22

Chua, W.F. (1986), Radical Developments in Accounting Thought, The Accounting Review, oktober 1986, pp. 601-632.

Dijksma, J. (red.) $(1986,1987,1989,1990)$ Jaar in-jaar uit, 4 delen, Wolters-Noordhoff, Groningen.

Edwards, E.O. en Ph.W. Bell (1961), The Theory and Measurement of Business Income, University of California Press.

Feenstra, D.W. (1985), Oordeelsvorming rond de externe verslaggeving, Wolters-Noordhoff, Groningen.

Feenstra, D.W. (1988), De beste stuurlui ...., oratie Open universiteit, Wolters-Noordhoff, Groningen. 


\section{MAB}

Foster, G. (1978), Financial Statement Analysis, Prentice-Hall, Englewood Cliffs.

Grady. P. (1965), An Inventory of Generally Accepted Accounting Principles for Business Enterprises, Accounting Research Study no. 7, American Institute of Certified Public Accountants.

Griffin, P.A. (ed.) (1987), Usefulness to Investors and Creditors of Information Provided by Financial Reporting, $2^{\text {nd }}$ ed., Research Report FASB, Connecticut.

De Groot, A.D. (1961), Methodologie: Grondslagen van onderzoek en denken in de gedragswetenschappen, Mouton en Co., 's-Gravenhage.

Huizenga, P.W. (1969), De jaarrekening van ondernemingen, Kiuwer, Deventer.

ljiri, Y. (1967), The Foundations of Accounting Measurement, Prentice-Hall, Englewood Cliffs.

Klaassen, J. (1975), De vervangingswaarde, theorie en toepassingen in de jaarrekening. Samsom, Alphen aan den Rijn.

Klaassen, J. en H. Schreuder (1984), Accounting research in The Netherlands, in A.G. Hopwood en H. Schreuder (eds.), European Contributions to Accounting Research, VU Uitgeverij, pp. 113-131.

Knoops, C.D. (1990), Paradigms in accounting theory, paper European Accounting Association, Boedapest.

Knoops, C.D. (1990), Positive Accounting Theory, in: C.D Knoops, J. Dijksma en W.M. du Pon (eds.), FMA-kroniek 1990, Wolters Noordhoff, Groningen.

Kuhn, T.S. (1962/1970), The Structure of Scientific Revolutions, The University of Chicago Press.

Lee, T.A. (1985), Income and Value Measurement, $3^{\text {rd }} \mathrm{ed}$., Van Nostrand Reinhold Co. Ltd., Wokingham.

Lee, T.A. en D.P. Tweedie (1977), The Private Shareholder and the Corporate Report, The Institute of Chartered Accountants.

Libby, R. (1973), Accounting and Human Information Processing: Theory and Applications, Prentice-Hall, Englewood Cliffs.

Limperg Instituut (1990), Risico's en oordeelsvorming in de accountantspraktijk.

Maijoor, S.J. (1991), The Economics of Accounting Regulation, dissertatie Rijksuniversiteit Limburg.
Nelson, C.L. (1973), A Priori Research in Accounting, in N. Dopuch en L. Revsine (eds.), Accounting Research 19601970: A Critical Evaluation, University of Illinois, pp. 3-19.

Parker, R.H. en G.C. Harcourt (eds.) (1969/1986), Readings in the Concept and Measurement of Income, Cambridge University Press.

Revsine, L. (1973), Replacement Cost Accounting, Prentice-Hall, Englewood Cliffs.

Schreuder, H. (1981), Maatschappelijke verantwoordelijkheid en maatschappelijke berichtgeving van ondernemingen, Stenfert Kroese, Leiden.

Stamp, E. (1980), Corporate Reporting: Its Future Evolution, Canadian Institute of Chartered Accountants.

Sterling, R.R. (1967), A Statement of Basic Accounting Theory: A Review Article, Journal of Accounting Research, voorjaar 1967, pp. 95-112.

Sterling, R.R. (1970), Theory of the Measurement of Enterprise Income, University Press of Kansas.

Sterling, R.R. (1990), Positive Accounting: An Assessment, Abacus, september 1990, pp. 97-135.

Thomas, A.L. (1969), The Allocation Problem in Financial Accounting Theory, Studies in Accounting Research no. 3, American Accounting Association.

Thomas, A.L. (1974), The Allocation Problem: Part Two, Studies in Accounting Research no. 9, American Accounting Association.

Traas, L. (1981), Over de noodzaak tot heroriëntering van de (klassieke) bedrijfseconomie, De Accountant, november 1981 pp. 146-155

Watts, R.L. en J.L. Zimmerman (1990), Positive Accounting Theory: A Ten Year Perspective, The Accounting Review, januari 1990, pp. 131-156.

Wells, M.C. (1976), A Revolution in Accounting Thought, The Accounting Review, juli 1976, pp. 471-482.

Whittington, G. (1986), Financial Accounting Theory: An Overview, British Accounting Review, pp. 4-41.

Whittington, G. (1987), Positive Accounting: A Review Article, Accounting and Business Research, pp. 327-336. 